\title{
Kripto Para Piyasalarında Etkinlik; Haftanın Günü Etkisi: Bitcoin ve Litecoin Örneği
}

\section{Öz}

Çalışmanın amacı; kripto para birimlerinden Bitcoin ve Litecoin piyasalarının etkinliğini ölçerek haftanın günü etkisinin varlığını 29.04.2013-29.02.2020 tarihleri arasında günlük kapanış fiyatları kullanılarak incelenmesidir. İlgili dönemlerde her iki para birimine ait piyasaların etkinliğini incelemede ARMA, haftanın günü etkisinin olup olmadığının tespitinde ise Kruskal Wallis $\mathrm{H}$ testinden faydalanılmıştır. Çalışmanın sonunda her iki kripto para biriminin getirilerinin bir önceki zamandan bağımsız hareket ettiği yani ilgili dönemde bu kripto para piyasalarının etkin piyasaya benzer özellik taşıdığı ve haftanın günü etkisinin de varlığına rastlanılmadığı tespit edilmektedir.

Anahtar Kelimeler: Haftanın Günü Etkisi, Etkinlik, Kripto paralar, Bitcoin, Litecoin.

\section{The Efficiency in Cryptocurrency Markets; The Day of the Week Effect: Bitcoin and Litecoin Example}

\begin{abstract}
The aim of the study is to examine presence of day of the week effect by measuring effectiveness of Bitcoin and Litecoin markets which are cryptocurrencies using daily closing prices between 29.04.2013 and 29.02.2020. In the related periods, ARMA was used to examine the effectiveness of the markets in both currencies and the Kruskal Wallis H test was used to determine whether or not there was an effect on the day of the week. At the end of the study, it is determined that the returns of both currencies act independently from the previous time, that is, the markets of these crypto currencies in the relevant period have feature similar to effective market and there is no day of the week effect.
\end{abstract}

Keywords: Day of the Week Effect, Efficiency, Cryptocurrency, Bitcoin, Litecoin.

*ORCID Doktora Öğrencisi, Dokuz Eylül Üniversitesi, İiBF, İşletme Bölümü, ftmylmz35@gmail.com

** ORCID Prof. Dr., Dokuz Eylül Üniversitesi, İIBF, İşletme Bölümü, cenk.akkaya@deu.edu.tr 


\section{Extended Abstract}

One of the important developments in financial world is the Efficient Market Hypothesis put forward by Eugene Fama in the 1970s. According to the Efficient Market Hypothesis, if prices can adapt quickly and accurately to new information entering the market, the market is effective.

Another important development in financial world is cryptocurrencies which are virtual coins. Bitcoin and Litecoin, two of the first of cryptocurrencies, are on the way to becoming the money of the future.

The aim of the study is to determine the existence of day of the week effect by measuring the efficiency of the Bitcoin and Litecoin markets. For this reason, daily closing prices were used between 29.04.201329.02.2020 for both cryptocurrencies. Prices for Bitcoin and Litecoin are taken from coinmarketcap.com web. Analyses have been made on the natural logarithmic returns of the price series of the relevant cryptocurrencies. In the study, to determine the stationarity the Extended Dickey Fuller, Phillips Perron unit root tests and Ljung-Box statistics based on Portmanteau test were used. Also, ARMA method used in modelling time series and Kruskal Wallis $\mathrm{H}$ test, which is not based on the parametric test were used in the study.

As a result of the study, it is determined that the series of Bitcoin and Litecoin variables are stable at the level (Table 2,3). According to the Ljung-Box Q2 statistics, $\mathrm{H}_{0}$ : No autocorrelation, is rejected as $\mathrm{p}=$ $0.00<0.05$ for all delays, and it is understood that the relevant series are stationary (Table 4). According to the result of the ARMA test, the variables of the ARMA $(2,2)$ model for Bitcoin and the ARMA $(1,1)$ model for Litecoin are not significant at the 1\% significance level (Table 5). Namely, it is determined that there is no significant relationship between both Bitcoin and Litecoin return series and the previous time, and the relevant markets have feature similar to effective market between 29.04.2013-29.02.2020. Kruskal Wallis $\mathrm{H}$ analysis was used to determine the existence of day-of-week effect in Bitcoin and Litecoin markets in the relevant periods, that is, whether the average daily returns from Bitcoin and Litecoin differ on certain days of the week. According to the results of the KWH test, it is determined that Bitcoin and Litecoin returns do not differ according to the days of the week, that is, there is no the day of the week effect (Table 6,7).

The reason why no anomalies were observed in the relevant periods in the study is the increase in the number of sources describing crypto currencies and the related system (articles, videos on the internet, etc.) and therefore it can be shown that all investors have the same knowledge and the same idea about the future of cryptocurrencies. 


\section{Giriş}

Finans dünyasında meydana gelen önemli gelişmelerden biri 1970'li yıllarda Eugene Fama'nın piyasa etkinliği çalışması ile ileri sürdüğü Etkin Piyasa Hipotezi'dir. Bu hipoteze göre fiyatlar piyasaya giren yeni bilgilere hızlı ve doğru bir şekilde adapte olabiliyorsa o piyasa etkindir (Karan, 2018: 277). Etkin piyasada fiyatlar "rassal yürüyüss" izlemektedir. Rassal yürüyüssten kasıt fiyat değişimlerinin birbirinden bağımsız ve rassal hareket etmesidir (Zeren vd., 2013: 143).

Fama (1970) Etkin Piyasa Hipotezini belli varsayımlar altında oluşturmuştur. Yatırımcıların yatırım kararını risk ve getiriye göre belirlemesi, yatırımcıların risk ve getiri beklentilerinin homojen olması, bilginin serbestçe elde edilmesi, düşük işlem maliyeti ve sürekli işlem ve geniş işlem hacmi bu varsayımlardan bazılarıdır (Öztin, 2007: 3; Ergün, 2009: $5)$.

Piyasaların etkinlik düzeyi piyasaya giren bilgi çeşidine göre üç gruba ayrılmaktadır. Bunlar; zayıf formda etkin piyasa, yarı güçlü formda etkin piyasa ve güçlü formda etkin piyasadır. Zayıf formda etkin piyasa, geçmiş tüm bilgilerin; yarı güçlü formda etkin piyasa, geçmiş ve kamuya açıklanan tüm bilgilerin ve güçlü formda etkin piyasa ise geçmiş, kamuya açıklanmış ve açıklanmamış tüm özel bilgilerin finansal araçların fiyatlarına yansıdığını ifade etmektedir.

Etkin Piyasa Hipotezi'nden bir yatırım aracının getirisinin zamandan bağımsız olduğu ve tüm zamanlarda elde edilecek ortalama getirinin aynı olduğu dolayısıyla normalüstü getiri elde edilmesinin mümkün olmadığı anlaşılmaktadır. Fakat literatürde gerek pay piyasasını gerekse tahvil, bono, altın, petrol ve vadeli işlem piyasasını test etmeye yönelik yapılan çalışmalar incelendiğinde etkin piyasa hipotezi ile çelişen bulgulara rastlanılmaktadır. Hipotezle bağdaşmayan, ters düşen bu bulgular için Türkçe'de kabul görmüş anomali (aykırılık, denksizlik, anomaly) terimi kullanılmaktadır (Karan, 2018:287).

Anomaliyi sadece finansal piyasalarda değil sosyal, siyasal ve kültürel olarak yaşamın her alanında da gözlemlemek mümkündür (Özmen, 1997: 11). Piyasalarda gözlemlenen çeşitli türde anomaliler vardır. Bunlardan çalışmamıza konu olan dönemsel (takvimsel, mevsimsel) anomalilerden haftanın günü etkisi (anomalisi) finansal araçların haftanın bazı günlerinde diğer günlere göre sürekli olarak daha fazla ya da daha düşük getiri sağlaması olarak ifade edilmektedir (Eyüboğlu, 2017: 69).

Yatırımcının, yatırım kararını etkileyen unsurlardan biri piyasanın etkin olup olmadığı bilgisidir. Yatırımcı bu bilgiye sahip olarak yaptığ 1 yatırımın olası sonuçları hakkında fikir sahibi olmakta ve bu ölçüde stratejiler geliştirebilmektedir. Özellikle, belli dönemlerde fiyatlarda meydana gelen dalgalanmalar yani dönemsel anomali varlığının tespiti, yatırımcıyı aşırı kayıplara karşı korumakta ya da aşırı getiri elde etmesini sağlamaktadır.

Teknolojinin gelişmesiyle finans dünyasında çı̆̆ır açan önemli gelişmelerden bir diğeri ise hiç şüphesiz kripto paralardır. Her geçen gün sayısı artan kripto paraların ilklerinden olan ve ilk çıtı̆̆ından beri dikkatleri üzerine çeken Bitcoin ve Litecoin geleceğin parası olma yolunda ilerleyen önemli teknolojilerdir. Yüksek işlem hacimleri ya da fiyatlarındaki aşırı oynaklık nedeniyle alternatif yatırım aracı olarak görülen Bitcoin ve Litecoin piyasalarının etkinliğini ölçmek, dolayısıyla haftanın günü etkisi varlığının tespiti yatırımcılar açısından önem taşımaktadır. Bu noktadan hareketle, çalışma giriş bölümünden sonra ikinci bölüm altında kripto paraların tanımı özellikle Bitcoin ve Litecoin kripto para birimi üzerinde durulmuştur. Üçüncü bölümde literatür kapsamında kripto para piyasalarının etkinliğini ölçerek 
haftanın günü etkisi varlığını araştıran güncel bazı çalışmalara, dördüncü bölümde veri seti ve yöntemlere, beşinci bölümde ise analiz ve bulgulara yer verilmiştir.

\section{Kripto Paralar: Bitcoin ve Litecoin}

Günümüzde internet üzerinde yapılan alışverişler ile gerçekleşen elektronik ödemeler için finansal kuruluşlar aracı olmaktadır. Bu sistemin işleyişinde yapılan çoğu işlemler modelin zayıflığından kaynaklı güven olgusunu zedelemektedir. Bu noktada, olası sistemden kaynaklı güven sorunu daha fazla güvene dayalı bir ödeme sisteminin doğmasına yani kripto paraların ortaya çıkmasına neden olmuştur (Nakamota, 2008:1).

2008 yılında kimliği hala tespit edilemeyen Japon programeı Satoshi Nakamoto tarafından yayınlanan İngilizce adı "Bitcoin: A Peer-to-Peer Electronic Cash System" Türkçe karşılığ1 ise "Bitcoin: Eş Seviyede Nakit Ödeme Sistemi" olan makaleyle hayatımıza girmeye başlayan kripto paralar şifreleme metodunu kullanan merkezi olmayan dijital para birimleridir (Çakın, 2019: 26).

Kripto paraların alımı ve satımı yapılan piyasalar resmî tatiller dahil olmak üzere kendi kurallar çerçevesinde 7 gün 24 saat açık olup sürekli olarak işlem halindedir. Günümüzde piyasada sayısı 5 binden fazla kripto para çeşidi bulunmaktır. Bunlardan bazıları Bitcoin, Ethereum, Litecoin, Dash, Monero, vb. (https://coinmarketcap.com/all/views/all/).

Piyasaya sürülen ilk kripto para birimi Bitcoin'dir. Satoshi Nakamoto tarafından üretilen Bitcoin ilk çıktığı andan günümüze kadar yaygın olarak kullanılmaktadır. Dolaşımdaki Bitcoin adedi yaklaşık olarak 18 milyondur (https://coinmarketcap.com/).

Bitcoin ile aynı yazılım diline sahip olan fakat bazı farklılıklarıyla yine de ilk olma özelliğini taşıyabilen ve 7 Ekim 2011 yılında piyasaya sürülen bir diğer kripto para birimi ise Litecoin'dir. Litecoin, Google mühendisi Charlie Lee tarafından geliştirilmekle birlikte, Bitcoin'e kıyasla bazı avantajlara sahiptir. Bu avantajlardan biri, Litecoin'in Bitcoin'den dört kat daha hızlı transfere sahip olmasıdır. Özellikle, bu konu müşterilerin ödemelerini daha hızlı onaylamasını sağlayan tüccarlar için önem taşımaktadır (Çakın, 2019: 47). Bir diğer avantaj ise Bitcoin'e göre daha fazla depolama ve çok daha düşük işlem maliyetli olmasıdır.

Litecoin, günümüzde en büyük piyasa değerine sahip dijital paralardan biridir ve piyasada dolaşan yaklaşık olarak 64 milyon 926 bin adedi bulunmaktadır (https://coinmarketcap.com/).

\section{Literatür Taraması}

Literatürde Bitcoin ve Litecoin başta olmak üzere diğer kripto para birimi piyasalarının etkinliğini ölçerek dönemsel anomalilerin özellikle bunlardan haftanın günü etkisinin olup olmadığını tespit eden sınırlı çalışma mevcut iken bunlardan güncel olanlar kronolojik sıraya göre aşağıdaki gibi özetlenmiştir.

Caporale ve Plastun (2017) 2013-2017 yılları arasında çeşitli parametrik, parametrik olmayan testler ve ticari simülasyon teknikleri (ortalama analiz, student t-testi, ANOVA, Kruskal-Wallis $\mathrm{H}$ testi ve kukla değişkenler ile regresyon analizi) kullanarak kripto para piyasasında haftanın günü etkisini incelemişlerdir. Elde edilen bulgulara göre, Bitcoin hariç çoğu kripto paralarda (Litecoin, Ripple, Dash) haftanın günü etkisine rastlanılmadığı tespit edilmiştir. Bitcoin'de Pazartesi günkü getirilerin haftanın diğer günlerin getirisine göre daha fazla olduğu ve dolayısıyla Bitcoin piyasasının etkin olmadığı saptanmıştır. 
Kurihara ve Fukushima (2017) 2010-2016 y1lları arasında Bitcoin fiyatlarında haftanın günü etkisinin varlığını sıradan ve güçlü en küçük kareler yöntemleri ile incelemişlerdir. Elde edilen bulgulara göre, cumartesi ve pazar günlerinin diğer günlere göre en fazla getiriye sahip olduğu ve Bitcoin piyasasının ilgili dönemlerde etkin olmadığ 1 tespit edilmiştir.

Durai ve Paul (2018), Bitcoin getirileri üzerinde haftanın günü etkisi yani takvimsel anomalinin varlığını 2010-2018 yılları arasında yuvarlama regresyon analizi ile incelemişlerdir. Elde edilen bulgulara göre, anomalinin gözlemlendiğini ve piyasanın ilgili dönemlerde etkin olmadığı saptanmıştır.

Yaya ve Ogbonna (2019), 2015-2019 yılları arasında on üç piyasa değeri yüksek olan kripto para (Bitcoin, Dash, Digibyte, Doge, Ethereum, Litecoin, Maidsafecoin, Monero, Nem, Ripple, Stellar, Verge,Vertcoin) fiyatlarında ve piyasa değerinde haftanın günü etkisinin varlığını kukla değişkenler ile fraktal bütünleşme regresyon analizi ile incelemişlerdir. Elde edilen bulgulara göre, kripto paraların hem getirileri ve hem de oynaklığı üzerinde haftanın günü etkisinin olmadığı sadece Bitcoin oynaklığ üzerinde pazartesi ve cuma günlerinin olası etkilerinin olduğu tespit edilmiştir. Ayrıca, Bitcoin piyasasının mükemmel derecede etkin olduğu elde edilen sonuçlar arasındadır.

Decourt vd. (2019) pay senedi ve bono piyasalarında tespit edilen pazartesi etkisinin Bitcoin piyasasındaki varlığını 2013-2018 yılları arasında student t-testi ve regresyon analizi ile incelemişlerdir. Çalışmanın sonunda Bitcoin piyasasının etkin olmadığı ve normalüstü getirilerin sağlandığ tespit edilmiştir. Pazartesi etkisinin olmadığı, salı ve çarşamba günlerdeki getirilerin ilgili dönemlerdeki Bitcoin getirisinin ortalaması üzerinde olduğu ve diğer hafta içi günlere kıyasla daha fazla olduğu saptanmıştır.

Ma ve Tanizaki (2019) Bitcoin piyasasında haftanın günü etkisini 2014-2018 yılları arasında doğrusal regresyon analizi ve yuvarlama pencere analizi ile incelemişlerdir. Bitcoin'in çeşitli para birimlerindeki (USD, EUR, CNY, JBY vb.) değerine bağlı olarak gerçekleşen analiz sonuçlarına göre piyasada haftanın günü etkisinin gözlemlendiği dolayısıyla piyasanın etkin olmadığ 1 tespit edilmiştir.

Aharon ve Qadan (2019) Bitcoin'in sadece getirilerinde değil aynı zamanda oynaklığında da haftanın günü etkisinin varlığını 2010-2017 yılları arasında günlük verileri kullanarak en küçük kareler yöntemi ve GARCH modelleri ile incelemişlerdir. Elde edilen bulgulara göre, haftanın günü anomalisinin Bitcoin'in hem oynaklığında hem de getirilerinde gözlemlendiği tespit edilmiştir. Dolayısıyla, bu piyasanın ilgili dönemlerde etkin olmadığı anlaşılmaktadır.

Robiyanto vd. (2019) kripto para piyasasında özellikle Bitcoin ve Litecoin'de haftanın günü etkisi ve yılın ayı etkisi varlığını 2014-2018 yılları arasında GARCH $(1,1)$ modelini kullanarak incelemişlerdir. Çalışmanın sonunda kripto para piyasasında haftanın günü ve yılın ayı anomalisinin gözlemlendiği bu yüzden piyasanın etkin olmadığ 1 tespit edilmiştir.

Evci (2020) 2013-2019 yılları arasındaki günlük fiyatları kullanarak Bitcoin fiyatlarında haftanın günü etkisinin varlığını asimetrik GARCH modeliyle incelemiştir. Elde edilen bulgulara göre, Bitcoin getirileri üzerinde pazartesi, perşembe ve pazar günlerinin negatif etkileri olduğu ve günlerden perşembe gününün en fazla kayıpla sonuçlandığı tespit edilmiştir. Çalışmada ilgili dönemlerde Bitcoin piyasasında haftanın günü etkisi gözlemlenerek piyasanın etkin olmadığ belirlenmiştir. 


\section{Veri Seti ve Yöntem}

Çalışmada Bitcoin ve Litecoin piyasalarının etkinliği incelenerek ilgili piyasalarda haftanın günü etkisinin olup olmadığının tespiti için 29.04.2013-29.02.2020 tarihleri arasındaki günlük kapanış fiyatları kullanılmıştır. Bitcoin ve Litecoin'e ait fiyatlar coinmarketcap.com web adresinden alınmıştır.

Çalışmada öncelikle Bitcoin ve Litecoin'e ait günlük fiyatların doğal logaritmik getirileri aşağıdaki formülden yararlanılarak hesaplanmıştır.

$$
\mathrm{R}_{\mathrm{t}}=\ln \left(\frac{\mathrm{P}_{\mathrm{t}}}{\mathrm{P}_{\mathrm{t}-1}}\right)
$$

Burada $\mathrm{R}_{\mathrm{t}}$ kripto paraların (Bitcoin ve Litecoin) $t$ dönemdeki getirisini, $\ln \left(\mathrm{P}_{\mathrm{t}}\right)$ ve $\ln \left(\mathrm{P}_{\mathrm{t}-1}\right)$ ise ilgili kripto paraların sırasıyla t ve t-1'deki logaritmik fiyatlarını göstermektedir.

Zaman serileri bir değişkenin ardışık dönemlerde gözlemlenen değerlerinin zamana bağ 1 olarak sıralanması ile oluşan sayı dizileri olarak tanımlanmaktadır (Akkaya vd., 2010: 59). Zaman serilerinde sahte regresyonun önüne geçmek diğer bir deyişle sahte ilişkilerinin oluşmasına önlemek ve doğru modellemeyi yapabilmek için durağanlığın test edilmesi gerekmektedir (Karcıoğlu ve Özer, 2017: 461). Durağanlık bir değişkenin zaman içerisinde sabit varyansa, otokovaryansa ve ortalamaya sahip olmasını ifade etmektedir. Çalışmada durağanlığın test edilmesinde Dickey ve Fuller (1981) tarafından geliştirilen Genişletilmiş Dickey-Fuller (Augmented Dickey-Fuller-ADF) ve Phillips ve Perron' un (1988) geliştirdiği Phillips Perron birim kök testlerinden ve Portmanteau testine dayalı Ljung-Box istatistiğinden faydalanılmıştır. Çalışmada zaman serisine bağlı olarak durağan zaman serilerinin modellenmesinde kullanılan ARMA yöntemine başvurulmuştur. Ayrıca çalışmada kullanılan diğer yöntem ise serilerin normal dağılım sergilememesi sonucunda parametrik teste dayalı olmayan Kruskal Wallis H testidir.

\subsection{Genişletilmiş Dickey-Fuller Testi (ADF)}

Genişletilmiş Dickey-Fuller Testi (ADF) zaman serisinin birim kök içerip içermediğini yani durağanlığını test etmede kullanılmaktadır. ADF testinin temel varsayımı hata terimlerinin sabit varyansa, normal dağılıma ve birbirinden bağımsız olmasına dayanmasıdır. Bu test aşağıdaki gibi üç ayrı denklem şeklinde ifade edilmektedir.

$$
\begin{aligned}
& \Delta \mathrm{Y}_{\mathrm{t}}=\delta \mathrm{Y}_{\mathrm{t}-1}+\sum_{\mathrm{i}=1}^{\mathrm{k}} \beta_{\mathrm{i}} \Delta \mathrm{Y}_{\mathrm{t}-\mathrm{i}}+\mathrm{u}_{\mathrm{t}} \\
& \Delta \mathrm{Y}_{\mathrm{t}}=\alpha_{0}+\delta \mathrm{Y}_{\mathrm{t}-1}+\sum_{\mathrm{i}=1}^{\mathrm{k}} \beta_{\mathrm{i}} \Delta \mathrm{Y}_{\mathrm{t}-\mathrm{i}}+\mathrm{u}_{\mathrm{t}} \\
& \Delta \mathrm{Y}_{\mathrm{t}}=\alpha_{0}+\alpha_{2 \mathrm{t}}+\delta \mathrm{Y}_{\mathrm{t}-1}+\sum_{\mathrm{i}=1}^{\mathrm{k}} \beta_{\mathrm{i}} \Delta \mathrm{Y}_{\mathrm{t}-\mathrm{i}}+\mathrm{u}_{\mathrm{t}}
\end{aligned}
$$

Burada k gecikme uzunluğunu, $\mathrm{t}$ zaman trendini $\mathrm{Y}_{\mathrm{t}-1}$ gecikmeli zaman trendini, $\Delta \mathrm{Y}_{\mathrm{t}} \mathrm{zaman}$ serisinin birinci farkını ve $u_{t}$ hata terimini ifade etmektedir. Üç denklemi birbirinden ayıran $\alpha_{0}$ ve $\alpha_{2 t}$ ise incelenen zaman serisinde tahmin edilebilir sistematik bir trendin olup olmadığını belirleyen katsayılardır. (3) no'lu denklemin ADF testinin tahmininde kullanılması tavsiye edilmektedir. ADF testi istatistiksel olarak $\delta=0$ (Birim kök vardır, seri durağan değildir) şeklinde kurulan $\mathrm{H}_{0}$ hipotezini test etmede kullanılmaktadır (Ergül, 2009:109-110). 


\subsection{Phillips -Perron (PP) Birim Kök Testi}

Phillips -Perron (PP) birim kök testi ADF testinin alternatifinden ziyade tamamlayıcı nitelik taşımaktadır. Bu test yüksek derecede korelasyonu kontrol etmek için kullanılan parametrik olmayan bir analizdir. Ayrıca, normal dağılım göstermeyen serilerde kullanılması tavsiye edilmekte olan PP testi ADF'nin aksine hata terimleri arasında zayıf bağımlılığa izin vermektedir (Ergül, 2009: 110). Bu test için hipotezler $\mathrm{H}_{0}$ : Seri birim kök içermektedir (durağan değildir); $\mathrm{H}_{1}$ : Seri birim kök içermemektedir (durağandır) şeklindedir.

\subsection{Portmanteau Testi}

Q istatistikleri olarak bilinen Portmanteau testi zaman serilerinde otokorelasyon olup olmadığının tespitinde kullanılmaktadır. Otokorelasyon olması demek hata terimlerinin birbirini takip eden değerleri arasında istatistiksel olarak anlamlı bir ilişki bulunması demektir. Bir seride otokorelasyonun varlığ 1 söz konusu ise serinin durağan olduğu diğer bir deyişle serinin rassal hareket etmediği anlaşılmalıdır.

Portmanteau testine dayalı test istatistikleri Ljung-Box ve Box Pierce istatistikleridir. Her ikisi de $X^{2}$ dağılımı göstermektedir. Ljung- Box istatistiği için kullanılan hipotezler aşağıdaki gibidir (Uyanık, 2014: 34-35):

$$
\begin{aligned}
& \mathrm{H}_{0}: \mathrm{p}_{1}=\mathrm{p}_{2}=\ldots=\mathrm{p}_{\mathrm{k}}=0 \text { (Otokorelasyon yoktur; Seriler rassaldır) } \\
& \mathrm{H}_{1}: \mathrm{p}_{1} \neq \mathrm{p}_{2} \neq \ldots=\mathrm{p}_{\mathrm{k}} \neq 0 \text { (Otokorelasyon vardır; Seriler rassal değildir) }
\end{aligned}
$$

\subsection{ARMA Modeli}

ARMA diğer bir deyişle Box-Jenkins yöntemi, durağan serilerde uygulanmaktadır. Bu yöntem; kesikli, stokastik ve doğrusal süreçlere dayanmaktadır. Yöntemin tahmin modelleri otoregresif, otoregresif hareketli ortalama ve birleştirilmiş otoregresif hareketli ortalamadır. Sadece ARMA $(p, q)$ durağan serilere uygulanmaz bu özel birleşimi oluşturan $\mathrm{AR}(p)$ ve $\mathrm{MA}(q)$ da durağan serilere uygulanmaktadır. ARMA (p,d,q) durağan olmayan zaman serilerinde kullanılmaktadır (Akkaya vd., 2010: 61).

$\mathrm{AR}(\mathrm{p})$ modelleri aşağıdaki gibi ifade edilmektedir:

$\mathrm{Y}_{\mathrm{t}}=\beta_{1} \mathrm{Y}_{\mathrm{t}-1}+\beta_{2} \mathrm{Y}_{\mathrm{t}-2}+\ldots+\beta_{\mathrm{p}} \mathrm{Y}_{\mathrm{t}-\mathrm{p}}+\delta+\mathrm{a}_{\mathrm{t}}$

Burada $\mathrm{Y}_{\mathrm{t}-1}, \mathrm{Y}_{\mathrm{t}-2}, \mathrm{Y}_{\mathrm{t}-3 \ldots} \ldots \mathrm{Y}_{\mathrm{t}-\mathrm{p}}$ geçmiş değerler, $\beta_{1}, \beta_{2} \ldots \beta_{\mathrm{p}}$ geçmiş değerlerin katsayıları, $\delta$ sabit bir değer, $a_{t}$ hata terimidir.

MA(q) modelleri ise aşağıdaki gibi ifade edilmektedir:

$\mathrm{Y}_{\mathrm{t}}=\mu+\mathrm{a}_{\mathrm{t}}+\theta_{1} \mathrm{a}_{\mathrm{t}-1}+\theta_{2} \mathrm{a}_{\mathrm{t}-2}+\ldots+\theta_{\mathrm{p}} \mathrm{a}_{\mathrm{t}-\mathrm{p}}$

Burada $\mu$ ortalamay1, at, at 1 , at-2...attp hata terimlerini, $\theta_{1}, \theta_{2}, \theta_{3} \ldots \theta_{\mathrm{p}}$ hata terimlerin katsayısını ifade etmektedir. Y zaman serisi hem AR hem de MA serisini taşıdığında ARMA olmaktadır. ARMA (p,q) modelleri aşağıdaki gibi ifade edilmektedir:

$$
\mathrm{Y}_{\mathrm{t}}=\beta_{1} \mathrm{Y}_{\mathrm{t}-1}+\beta_{2} \mathrm{Y}_{\mathrm{t}-2}+\ldots+\beta_{\mathrm{p}} \mathrm{Y}_{\mathrm{t}-\mathrm{p}}+\delta+\mathrm{a}_{\mathrm{t}}+\theta_{1} \mathrm{a}_{\mathrm{t}-1}+\theta_{2} \mathrm{a}_{\mathrm{t}-2}+\ldots+\theta_{\mathrm{p}} \mathrm{a}_{\mathrm{t}-\mathrm{p}}
$$




\subsection{Kruskal Wallis H Testi}

Kruskal Wallis $\mathrm{H}$ testi normal dağılım göstermeyen serilerde tek yönlü varyans analizinin parametrik olmayan karşılığıdır. $\mathrm{K}$ tane bağımsız örneklemin ortalamalarının karşılaştırılmasında kullanılmaktadır.

\section{Analiz ve Bulgular}

İlgili dönemlerde Bitcoin ve Litecoin piyasalarına ait etkinliği ölçmede ADF, PP, Ljung-Box ve ARMA testlerinden yararlanılmıştır.

Tablo 1: Bitcoin ve Litecoin'in Günlük Getirilerine Ait Tanımlayıcı İstatistikleri

\begin{tabular}{|c|c|c|c|c|c|c|c|c|}
\hline & Ortalama & Medyan & Maksimum & Minimum & $\begin{array}{c}\text { St. } \\
\text { Sapma }\end{array}$ & Çarpıklık & Basıklık & $\begin{array}{c}\text { Jargue- } \\
\text { Bera } \\
\text { (Olasılık) }\end{array}$ \\
\hline Bitcoin & 0.001636 & 0.00177 & 0.35745 & -0.26620 & 0.0423 & -0.1515 & 10.805 & $\begin{array}{l}6349.0 \\
(0.000)\end{array}$ \\
\hline Litecoin & 0.001038 & -0.0005 & 0.82896 & -0.51393 & 0.064 & 1.6987 & 28.472 & $\begin{array}{l}68708.4 \\
(0.000)\end{array}$ \\
\hline
\end{tabular}

Tablo 1, Bitcoin ve Litecoin'in günlük getirilerine ait tanımlayıcı istatistiklerini göstermektedir. Bitcoin getiri serisine ait çarpıklık katsayısı negatif olduğundan serinin soldan çarpık olduğu tespit edilmiştir. Litecoin getiri serisine ait çarpıklık katsayısı ise pozitif olduğundan bu serinin sağa çarpık olduğu saptanmıştır. Her iki getiri serisine ait basıklık katsayısı üçten büyük olması (aşırı basıklık) serilerin leptokurtik dağılıma sahip olduklarını göstermektedir. Bu tarz özelliklere sahip seriler zaman serisi niteliği taşımaktadır. Jargue-Bera istatistiğine göre $\mathrm{H}_{0}$ : Seriler normal dağılmaktadır şeklinde kurulan sıfır hipotez $\mathrm{p}=0.000<0.05$ olduğundan reddedilmektedir. Yani her iki kripto paraya ait getiri serileri normal dağılmamaktadır. Tablo 1'e göre, çalışma kapsamında ele alınan dönemlerde yatırımcısına yaklaşık \%0.828 ile günlük en yüksek getiri sağlayan yine yaklaşık \%0.503 ile en fazla kaybı sağlayan kripto para birimi Litecoin olmuştur.

Tablo 2: Bitcoin ve Litecoin'in Günlük Getiri Serilerine Ait ADF Birim Kök Testi Sonuçları

\begin{tabular}{|c|c|c|c|c|}
\hline & \multicolumn{2}{|c|}{ Sabitli Trendsiz } & \multicolumn{2}{c|}{ Sabitli Trendli } \\
\hline & ADF & Olasılık Dĕ̆geri (P) & ADF & Olasılık Değeri (P) \\
\hline Bitcoin & -49.91912 & 0.0001 & -49.91000 & 0.0000 \\
\hline Litecoin & -48.85761 & 0.0001 & -48.84838 & 0.0000 \\
\hline
\end{tabular}

Tablo 2, Bitcoin ve Litecoin'in günlük getiri serilerine ait ADF birim kök testi sonuçlarını göstermektedir. ADF birim kök testi sonuçlarına göre her iki kripto para birimine ait getiri serisinin düzeyde sabitli trendsiz ve sabitli trendli olarak $\mathrm{H}_{0}$ :Seriler birim kök içermektedir şeklinde kurulan sıfır hipotezi $\mathrm{p}=0.000<0.05$ olduğundan reddedilmekte serilerin birim kök içermediği için durağan olduğu anlaşılmaktadır. 
Tablo 3: Bitcoin ve Litecoin'in Günlük Getiri Serilerine Ait PP Birim Kök Testi Sonuçları

\begin{tabular}{|c|c|c|c|c|}
\hline & \multicolumn{2}{|c|}{ Sabitli Trendsiz } & \multicolumn{2}{c|}{ Sabitli Trendli } \\
\hline & PP & Olasılık Değgeri (P) & PP & Olasılık Değeri (P) \\
\hline Bitcoin & -50.07848 & 0.0001 & -50.06947 & 0.0000 \\
\hline Litecoin & -49.05349 & 0.0001 & -49.04469 & 0.0000 \\
\hline
\end{tabular}

Tablo 3, Bitcoin ve Litecoin'in günlük getiri serilerine ait Phillips-Perron birim kök testi sonuçlarını göstermektedir. Tablo 3 göre her iki değişkene ait getiri serilerin düzeyde sabitli trendsiz ve sabitli trendli olarak \%5 anlamlılık seviyesinde birim kök içermediği dolayısıyla durağan olduğu saptanmaktadır.

Tablo 4: Ljung-Box Otokorelasyon Test Sonuçları

\begin{tabular}{|c|c|c|c|c|}
\hline \multirow[b]{2}{*}{ Gecikme Sayısı } & \multicolumn{2}{|c|}{ Bitcoin } & \multicolumn{2}{|c|}{ Litecoin } \\
\hline & $\begin{array}{c}\text { Ljung-Box } \\
\text { Q istatistiği }\end{array}$ & Olasılık Değeri (P) & $\begin{array}{l}\text { Ljung-Box } \\
\text { Q istatistiği }\end{array}$ & Olasılık Değeri (P) \\
\hline 1 & 0.0008 & 0.978 & 1.1924 & 0.275 \\
\hline 2 & 0.3324 & 0.847 & 2.9198 & 0.232 \\
\hline 3 & 0.3721 & 0.946 & 2.9200 & 0.404 \\
\hline 4 & 1.6187 & 0.805 & 7.4896 & 0.112 \\
\hline 5 & 6.5899 & 0.253 & 8.6329 & 0.125 \\
\hline 6 & 15.307 & 0.018 & 29.862 & 0.000 \\
\hline 7 & 15.544 & 0.030 & 30.563 & 0.000 \\
\hline 8 & 15.940 & 0.043 & 35.198 & 0.000 \\
\hline 9 & 16.181 & 0.063 & 35.263 & 0.000 \\
\hline 10 & 24.693 & 0.006 & 35.366 & 0.000 \\
\hline 11 & 33.080 & 0.001 & 37.362 & 0.000 \\
\hline 12 & 33.123 & 0.001 & 37.831 & 0.000 \\
\hline 13 & 33.370 & 0.001 & 38.060 & 0.000 \\
\hline 14 & 33.846 & 0.002 & 39.937 & 0.000 \\
\hline 15 & 33.869 & 0.004 & 40.719 & 0.000 \\
\hline 16 & 34.366 & 0.005 & 41.921 & 0.000 \\
\hline & $\begin{array}{c}\text { Ljung-Box } \\
\mathrm{Q}^{2} \text { istatistiği }\end{array}$ & Olasılık Değeri (P) & $\begin{array}{c}\text { Ljung-Box } \\
\mathrm{Q}^{2} \text { istatistiği }\end{array}$ & Olasılık Değeri (P) \\
\hline 1 & 227.52 & 0.000 & 95.969 & 0.000 \\
\hline 2 & 280.80 & 0.000 & 104.36 & 0.000 \\
\hline 3 & 345.44 & 0.000 & 110.52 & 0.000 \\
\hline 4 & 360.35 & 0.000 & 112.89 & 0.000 \\
\hline 5 & 403.18 & 0.000 & 113.89 & 0.000 \\
\hline 6 & 412.90 & 0.000 & 119.45 & 0.000 \\
\hline 7 & 427.12 & 0.000 & 124.97 & 0.000 \\
\hline 8 & 455.12 & 0.000 & 216.73 & 0.000 \\
\hline 9 & 467.95 & 0.000 & 429.15 & 0.000 \\
\hline 10 & 520.60 & 0.000 & 439.95 & 0.000 \\
\hline 11 & 555.64 & 0.000 & 465.22 & 0.000 \\
\hline 12 & 592.04 & 0.000 & 469.55 & 0.000 \\
\hline 13 & 643.89 & 0.000 & 476.21 & 0.000 \\
\hline 14 & 666.00 & 0.000 & 479.95 & 0.000 \\
\hline 15 & 686.68 & 0.000 & 483.13 & 0.000 \\
\hline 16 & 694.22 & 0.000 & 483.80 & 0.000 \\
\hline
\end{tabular}

Bitcoin ve Litecoin getiri serilerinde otokorelasyon olup olmadiğ 1 Portmanteau testine dayalı Ljung-Box Q analizi ile test edilmiştir. Hata terimleri arasındaki ilişki Ljung-Box Q ile hata terimlerinin kareleri arasındaki ilişki ise Ljung-Box $Q^{2}$ istatistiği ile incelenmiştir.

Tablo 4'teki test sonuçlarına göre her iki kripto paranın ilk 5 gecikmesinde otokorelasyon sorunu yok iken 6 gecikmeden itibaren bu sorun yeniden ortaya çıkmaktadır. Ljung-Box $\mathrm{Q}^{2}$ 
istatistiğine göre ise tüm gecikmeler için $\mathrm{H}_{0}$ : Otokorelasyon yoktur şeklinde kurulan sıfir hipotez $\mathrm{p}=0.00<0.05$ olduğundan reddedilerek serilerin durağan olduğu anlaşılmaktadır.

Tablo 5: Bitcoin ve Litecoin' e Ait ARMA Modeli Sonuçları

\begin{tabular}{|c|c|c|c|c|c|}
\cline { 2 - 5 } \multicolumn{1}{c|}{} & Değișken & Katsayı & St. Sapma & t-istatistiği & $\begin{array}{c}\text { Olasılık } \\
\text { Dĕ̆geri (P) }\end{array}$ \\
\hline \multirow{3}{*}{ Bitcoin } & $\mathrm{C}$ & 0.001770 & 0.000844 & 2.098546 & 0.0360 \\
\cline { 2 - 6 } & $\mathrm{AR}(2)$ & 0.2900532 & 0.205590 & 1.413165 & 0.1577 \\
\cline { 2 - 6 } & $\mathrm{MA}(2)$ & -0.292681 & 0.206333 & -1.418488 & 0.1562 \\
\hline \multirow{3}{*}{ Litecoin } & $\mathrm{C}$ & 0.001040 & 0.001306 & 0.796151 & 0.4260 \\
\cline { 2 - 6 } & $\mathrm{AR}(1)$ & -0.417229 & 0.523316 & -0.797278 & 0.4254 \\
\cline { 2 - 6 } & $\mathrm{MA}(1)$ & 0.441502 & 0.516588 & 0.854649 & 0.3928 \\
\hline
\end{tabular}

Tablo 5, Bitcoin ve Litecoin'e ait ARMA modeli sonuçlarını göstermektedir. Bu sonuçlara göre Bitcoin için $\operatorname{ARMA}(2,2)$, Litecoin için ise $\operatorname{ARMA}(1,1)$ modelinin değişkenleri $\% 1$ anlamlılık seviyesinde anlamlı olmadığı tespit edilmektedir. Bu noktada, hem Bitcoin hem de Litecoin getiri serilerinin kendinden bir önceki zamanla arasında anlamlı bir ilişki olmadığı, her iki para birimine ait getirilerin ilgili dönemlerde (29.04.2013-29.02.2020) rassal hareket ettiği saptanmaktadır. Fiyatların rassal hareket etmesi piyasanın etkin olması ile ilişkili olduğundan çalışmaya konu olan ilgili kripto paralar ilgili dönemde etkin piyasaya benzer özellik göstermektedir.

İlgili dönemlerde Bitcoin ve Litecoin piyasalarında haftanın günü etkisi varlığını yani Bitcoin ve Litecoin'den elde edilen ortalama günlük getirilerin haftanın belli günlerinde farklılaşıp farklılaşmadığının tespiti için Kruskal Wallis $\mathrm{H}$ analizinden yararlanılmıştır. Buna göre KWH testi için kurulan $\mathrm{H}_{0}$ hipotezi $\mathrm{H}_{0}$ : "x" kripto paranın ortalama günlük getirilerinin haftanın günleri arasında farklılaşmamaktadır şeklinde iken alternatif hipotez $\mathrm{H}_{1}$ : " $\mathrm{x}$ " kripto paranın ortalama günlük getirilerinin haftanın günleri arasında farklılaşmaktadır şeklinde olmaktadır.

Tablo 6: Bitcoin Haftanın Günü Getirilerinin Kıyaslanmasına İlişkin Kruskal Wallis H (KWH) Testi Sonuçları

\begin{tabular}{|c|c|c|c|c|}
\hline \multirow[b]{2}{*}{ Günler } & \multicolumn{4}{|c|}{ Bitcoin } \\
\hline & $\begin{array}{c}\text { Sira } \\
\text { Ortalaması }\end{array}$ & $\begin{array}{c}\text { Sayı(N) } \\
\text { Toplam } \\
(2497) \\
\end{array}$ & Kruskal Wallis Testi & $\begin{array}{c}\text { Olasılık } \\
\text { Değeri (P) }\end{array}$ \\
\hline Pazartesi & 1291.04 & 356 & 5.299 & 0.506 \\
\hline Sal1 & 1271.72 & 357 & & \\
\hline Çarşamba & 1200.61 & 357 & & \\
\hline Perşembe & 1204.25 & 357 & & \\
\hline Cuma & 1270.00 & 357 & & \\
\hline Cumartesi & 1270.41 & 357 & & \\
\hline Pazar & 1235.05 & 356 & & \\
\hline
\end{tabular}

Tablo 6, Bitcoin'e ait ortalama günlük getirilerin kıyaslanmasına ilişkin Kruskal Wallis $\mathrm{H}$ testi sonuçlarını göstermektedir. $\mathrm{P}=0.506>0.05$ olduğundan $\mathrm{H}_{0}$ kabul edilmekte dolayısıyla Bitcoin'e ait her bir güne ilişkin ortalama getirinin aynı olduğu saptanmaktadır. 
Tablo 7: Litecoin Haftanın Günü Getirilerinin Kıyaslanmasına İlişkin Kruskal Wallis H (KWH) Testi Sonuçları

\begin{tabular}{|c|c|c|c|c|}
\hline & \multicolumn{3}{|c|}{ Litecoin } \\
\hline Günler & $\begin{array}{c}\text { Sira } \\
\text { Ortalaması }\end{array}$ & $\begin{array}{c}\text { Sayı(N) } \\
\text { Toplam } \\
\mathbf{( 2 4 9 7 )}\end{array}$ & Kruskal Wallis Testi & $\begin{array}{c}\text { Olasıllk } \\
\text { Değeri (P) }\end{array}$ \\
\hline Pazartesi & 1215.72 & 356 & & 0.353 \\
\hline Salı & 1252.03 & 357 & & \\
\hline Çarşamba & 1191.18 & 357 & & \\
\hline Perşembe & 1221.39 & 357 & & \\
\cline { 1 - 2 } Cuma & 1284.47 & 357 & & \\
\hline Cumartesi & 1287.05 & 357 & & \\
\hline Pazar & 1291.19 & 356 & & \\
\cline { 1 - 2 }
\end{tabular}

Tablo 7, Litecoin'e ait ortalama günlük getirilerin kıyaslanmasına ilişkin Kruskal Wallis $\mathrm{H}$ testi sonuçlarını göstermektedir. Tablo 7'ye göre Litcoin'in ortalama getirilerinin günler arasında farklılaşmadığını $\mathrm{p}=0.353>0.05$ olduğundan $\mathrm{H}_{0}$ kabul edilmekle tespit edilmektedir.

KWH testi sonucuna göre haftanın günlerine göre Bitcoin ve Litecoin getirilerinin farklılaşmadığını yani haftanın günü etkisinin olmadığı tespit edilmektedir. Bu çalışma literatürde Yaya ve Ogbonna'nın (2019) 2015-2019 tarihleri arasında fraktal bütünleşme regresyon analizi kullanarak içlerinde Bitcoin ve Litecoin'in de olduğu on üç piyasa değeri yüksek olan kripto paraların getirileri üzerinde haftanın günü etkisinin olmamasının tespiti bakımından benzerlik taşımaktadır.

\section{Sonuç}

Küreselleşme ile birlikte ülkeler arasında kalkan ticaret sınırı, mevcut sisteme olan güvensizlik okların yönünü ulusal paralardan kripto paralara çevirmektedir. Mal ve hizmetlerin artık bu paralar aracılığıyla kolay bir şekilde sağlanması, işlem maliyetlerinin düşüklüğü, yüksek getiri sağlaması, kolay ve hızlı transferi sayesinde kripto paralara ilgi artmaktadır. Özellikle, ilk üretildiği andan günümüze kadar artma eğilimli işlem hacmine sahip olan Bitcoin ve Litecoin kripto para piyasaları için etkinliği ölçmek yani normal üstü getiri sağlanıp sağlanmadığını incelemek en çok merak edilen konular arasında yerini almaktadır.

$\mathrm{Bu}$ amaçla oluşturulan çalışmada 29.04.2013- 29.02.2020 dönemleri arasında Bitcoin ve Litecoin piyasalarının etkinliği ölçülerek haftanın günü etkisinin varlığı incelenmiştir. Çalışma kapsamında ADF, PP, Ljung-Box, ARMA ve KWH testleri uygulanmıştır. Zaman serisi analizinin sonucuna göre ilgili dönemlerde her iki piyasa için günlük getiri serilerinin rassal hareket ettiği dolayısıyla etkin piyasaya benzer özellik gösterdikleri saptanmıştır. Bilindiği üzere etkin bir piyasada geçmiş fiyatları, teknik ya da temel analiz tekniğini kullanarak ya da herhangi özel bir bilgiye sahip olarak normalüstü getiri elde edilmesi mümkün değildir. $\mathrm{Bu}$ açıdan ilgili dönemlerde ilgili piyasalarda anomali gözlenmediği bunu doğrulayan haftanın günü etkisinin varlığı için yapılan KWH testinin sonucunda da herhangi bir güne ait aşırı ya da düşük getiri elde edilemediği saptanmıştır.

Bitcoin ve Litecoin piyasasının oluştuğu ilk yıllarda piyasayı test etmeye yönelik yapılan ilk ampirik çalışmalarda anomali gözlendiği saptanmıştır. Diğer çalışmaların aksine bu çalışmada ilgili dönemlerde anomali gözlenmemesinin sebebi kripto paraları ve ilgili sistemi anlatan kaynakların sayısının artması (internette videolar, makale vb.) dolayısıyla tüm 
yatırımcıların aynı bilgiye ve kripto paraların geleceği hakkında aynı fikre sahip olması gösterilebilir.

\section{Kaynakça}

Aharon, D.Y. \& Qadan, M. (2019). Bitcoin and the day-of-the-week effect. Finance Research Letters, 31, 415-424.

Akkaya, G. C., Demireli, E. \&İbaş, E. (2010). Finansal piyasa etkinliği: S\&P 500 üzerine bir uygulama. C. Ü. İktisadi ve İdari Bilimler Dergisi, 11(2), 53-66.

Caporale, G. M. \& Plastun, A. (2017). The Day of the Week Effect in the Crypto Currency Market. https://www.econstor.eu/bitstream/10419/172992/1/cesifo1_wp6716.pdf (ET:28.05.2020).

Çakın, M. (2019). Kripto paralar: Bitcoin döviz kurlart ve alternatif kripto paralar arasındaki ilişkinin incelenmesi. (Yayınlanmamış Yüksek Lisans Tezi). Dokuz Eylül Üniversitesi Sosyal Bilimler Enstitüsü. İzmir.

Decourt, R. F., Chohan, U. W. \& Perugini, M. L. (2019). Bitcoin Returns and the Weekday Effect. https://papers.ssrn.com/sol3/papers.cfm?abstract_id=3435176 (ET: 28.05.2020).

Durai, R. S. S. \& Paul, S. (2018). Calendar Anomaly and the Degree of Market Inefficiency of Bitcoin. http://www.mse.ac.in/wp-content/uploads/2018/05/Working-Paper-168.pdf (ET:28.05.2020).

Ergül, N. (2009). Ulusal Hisse Senetleri Piyasası'nda Etkinlik. Yönetim Bilimleri Dergisi, 7, (1), 101-117.

Ergün, B. (2009). Piyasa anomalileri ve aşırı tepki hipotezinin IMKB'de araştırılması. (Yayınlanmamış Yüksek Lisans Tezi). Çukurova Üniversitesi Sosyal Bilimler Enstitüsü. Adana.

Eyüboğlu, K. (2017). Dünya Borsalarında Takvimsel Anomaliler. https://www.researchgate.net/publication/312575684 (ET:12.06.2020).

Evci, S. (2020). Bitcoin Piyasasında Haftanın Günü Anomalisi. Alanya Akademik Bakış Dergisi, 4(1), 53-61.

Karan, M. (2018). Yatırım Analizi ve Portföy Yönetimi (5.Baskı). Ankara. Gazi Kitabevi.

Karcıoğlu, R. \& Özer, N. (2017). BİST’ de Haftanın Günü ve Tatil Etkisi Anomalilerinin Getiri ve Oynakl1k Üzerindeki Etkisinin İncelenmesi. KTÜ Sosyal Bilimler Enstitüsü Sosyal Bilimler Dergisi, 14, 457-483.

Kurihara, Y. \& Fukushima, A. (2017). The Market Efficiency of Bitcoin: A Weekly Anomaly Perspective. Journal of Applied Finance \& Banking, 7(3), 57-64.

Ma, D. \& Tanizaki, H. (2019). On the day-of-the-week effects of Bitcoin markets: international evidence. China Finance Review International, 9(4), 455-478.

Nakamota, S. (2008). Bitcoin: A Peer-to-Peer Electronic Cash System. https://bitcoin.org/bitcoin.pdf (ET:10.05.2020).

Özmen, T. (1997). Dünya Borsalarında Gözlemlenen Anomaliler ve İstanbul Menkul Kıymetler Borsası Üzerine Bir Deneme. Ankara. SPK Yayınları.

Öztin, D. (2007). Dünya borsalarında gözlemlenen dönemsel anomaliler ve 1996-2006 dönemi için IMKB'de dönemsel anomalilerin incelenmesi. (Yayınlanmamış Yüksek Lisans Tezi). İstanbul Üniversitesi Sosyal Bilimler Enstitüsü. İstanbul.

Robiyanto, R., Susanto, Y. A. \& Ernayani, R. (2019). Examining the day-of-the-week-effect and the-month-of-the-year-effect in cryptocurrency market. Jurnal Keuangan dan Perbankan, 23(3), $361-375$. 
Uyanık, Ü. (2014). Zaman serilerinde yapısal kırılma ve vergi affi üzerine bir uygulama. (Yayınlanmamış Yüksek Lisans Tezi). Dokuz Eylül Üniversitesi Sosyal Bilimler Enstitüsü. İzmir.

Yaya, O. S. \& Ogbonna, A. E. (2019). Do we Experience Day- of-the- week Effects in Returns and Volatility of Cryptocurrency. https://www.researchgate.net/publication/330354052 (ET: 28.05.2020).

Zeren, F., Kara, H. \&Arı, A. (2013). Piyasa etkinliği hipotezi: İMKB için ampirik bir analiz. Dumlupınar Üniversitesi Sosyal Bilimler Dergisi, (36),141-148.

https://coinmarketcap.com/ (ET: 28.05.2020).

https://coinmarketcap.com/all/views/all/ (ET: 28.05.2020). 